\title{
Penggunaan Compost Tea yang Diinduksi Inokulum Fungi Lignoselulolitik Pada Media Tanam Cocopeat Terhadap Pertumbuhan Tanaman Kailan (Brassica oleracea L.).
}

\section{The Use of Compost Tea Induced by Lignocellulolytic Inoculum on Cocopeat Planting Media on the Growth of Kailan (Brassica oleracea L.).}

\author{
Sally Khoirunisa ${ }^{1)}$, Bambang Irawan ${ }^{1)}$, Rochmah Agustrina ${ }^{1)}$, Endang \\ Nurcahyani ${ }^{1)}$ Sri Wahyuningsih ${ }^{1)}$ \\ ${ }^{1}$ Biologi FMIPA, Universitas Lampung, Bandar Lampung, Indonesia \\ *Email : sallykhoirunisa11@gmail.com
}

\begin{abstract}
Compost tea is a compost extract that has many nutrients. In addition, the planting medium is also important in plant cultivation. Cocopeat is very suitable for growing media because it can store nutrients and water. The purpose of this study was to determine the effect of giving compost tea induced by lignocellulolytic fungi on cocopeat media on the growth of kailan (Brassica oleracea L.) and to determine the type of compost tea and the best media composition on the growth of kailan plants. This research was conducted from May to July 2020 in the greenhouse of the Integrated Field Laboratory, Faculty of Agriculture, University of Lampung. The research was conducted factorial using a completely randomized design (CRD) consisting of 2 factors, factor I was compost tea (A) with 2 levels of treatment, namely: compost tea aeration (A1) and compost tea nonaeration (A2). The second factor is the planting medium $(B)$ with 3 levels of treatment ratio, namely: cocopeat and soil with a ratio of 2: 1 (B1); 1: 1 (B2); 1:2 (B3) to obtain 6 treatment units. The control was not part of the treatment but the control was included in the graph as a comparison between treatments. The treatment was repeated 4 times. The parameters observed were plant height. The measurement data obtained were tested by the ANARA test. If there are differences in treatment, continue with the Tukey's test. The results showed that compost tea aerated (ACT) gave a higher average yield compared to compost tea noneration (NACT) while the composition of the planting medium for cocopeat: soil =1: 2 gave a higher average yield than other media compositions.
\end{abstract}

Keywords: Brassica oleracea L. cocopeat, compost tea, growth.

Disubmit : 19 Oktober 2020; Diterima: 20 Desember 2020; Disetujui : 29 April 2020

\section{PENDAHULUAN}

Akhir-akhir ini banyak kondisi tanah di Indonesia yang mengalami penurunan kesuburannya. Menurunnya kesuburan tanah dapat menjadi faktor utama yang dapat mempengaruhi produktivitas tanah, sehingga penambahan unsur hara dalam tanah sangat penting (Pinatih et al., 2015). Upaya yang banyak dilakukan petani adalah dengan pemberian pupuk sintetik. Pemberian pupuk sintetik yang berlebihan dan terus menerus akan berdampak negatif karena menyebabkan pencemaran lingkungan. Solusi yang tepat yaitu dengan menggunakan pupuk organik (kompos). Proses dekomposisi kompos secara alami berlangsung lama 
namun, dapat dipercepat bila dibantu inokulum fungi diantaranya Aspergillus sp. dan Trichoderma sp. (Antonius, 2015). Kompos biasanya dalam bentuk padat tetapi ada juga yang berbentuk cair yaitu compost tea. Compost tea adalah kompos padat yang diberi air sebagai larutan pengekstraknya. Menurut (Berek, 2017) compost tea lebih mudah diserap tanaman dan mengandung mikroba yang dapat meningkatkan pertumbuhan tanaman. Hasil penelitian (Bria, 2016) membuktikan bahwa jenis dan konsentrasi compost tea tertentu berpengaruh terhadap pertumbuhan tanaman bayam merah. (Shrestha et al., 2012) menyatakan pemberian compost tea mampu meningkatkan pertumbuhan dan produksi tanaman, serta menekan serangan hama dan penyakit.

Faktor penting lain dalam budidaya tanaman adalah media tanam. Cocopeat sangat cocok untuk dijadikan media tanam karena mampu menyimpan nutrisi dan air dalam jumlah yang banyak. Binawati, (2012) membuktikan bahwa pemanfaatan cocopeat pada bawang merah dapat meningkatkan pertumbuhan dan produksi tanaman. Pada penelitian ini diajukan pengujian dampak pemberian compost tea yang diinduksi inokulum fungi lignoselulolitik dan media tanam cocopeat pada pertumbuhan tanaman kailan (Brassica oleracea L.). Menurut (Singh and Sharma, 2002) fungi selulolitik Aspergillus sp. dapat mendegradasi selulosa sedangkan fungi lignolitik Trichoderma sp. dapat mendegradasi lignin. Pemberian Aspergillus sp. dan Trichoderma sp. pada limbah organik selain mempercepat waktu dekomposisi juga dapat meningkatkan kualitas kompos sehingga sangat baik jika digunakan sebagai campuran pada kompos karena akan meningkatkan hasil tanaman.

Kailan dijadikan tanaman uji coba karena mengandung gizi yang baik sehingga memberikan prospek yang bagus di bidang pertanian. Sebagai sayuran yang sudah dikenal dan banyak disukai masyarakat, kailan (Brassica oleracea L.) memiliki kandungan gizi yang baik diantaranya vitamin A, B, C, niacin, dan mineral, seperti : Ca, P, Na, F, S dan Cl yang baik bagi tubuh (Pracaya, 2005). Tanaman ini dapat mencegah kanker, mengatur tekanan darah, memperbaiki proses pencernaan. Hampir semua bagian tanaman kalian dapat dikonsumsi, daun, batang dan bunganya. Dengan keunggulan yang dimiliki oleh kailan, maka kailan menjadi sayuran yang digemari dan mempunyai nilai jual yang tinggi (Krisnawati, 2014)

\section{METODE PENELITIAN}

Penelitian ini akan dilaksanakan pada bulan Mei sampai dengan Juli 2020 di green house Laboratorium Lapang Terpadu Fakultas Pertanian Universitas Lampung pada bulan Mei sampai Juni 2020. Penelitian dilaksanakan secara faktorial menggunakan Rancangan Acak Lengkap (RAL) terdiri dari 2 faktor, Faktor I adalah compost tea (A) dengan 2 taraf perlakuan yaitu : compost tea aerasi (A1) dan compost tea nonaerasi (A2). Faktor II adalah media tanam (B) dengan 3 taraf perlakuan rasio, yaitu : cocopeat dan tanah dengan perbandingan 2:1 (B1); 1:1 (B2); 1:2 (B3) sehingga diperoleh 6 unit perlakuan. Penelitian ini terdapat kontrol yaitu tanaman yang tidak diberi compost tea dan media tanam cocopeat dikarenakan kontrol bukan bagian dari perlakuan. Jadi, data kontrol tidak dimasukkan ke dalam analisis ragam (ANARA) tetapi di dalam grafik data kontrol dimasukkan sebagai perbandingan antar perlakuan. Setiap perlakuan diulang sebanyak 4 kali.

\section{Prosedur kerja}

Pembuatan Compost tea. Kompos yang telah diinduksi fungi lignoselulolitik dan air dimasukkan ke dalam ember dengan perbandingan 1 bagian kompos : 5 bagian air ( $\mathrm{kg}: \mathrm{L})$. Compost tea yang diaerasi selama pembuatannya disebut compost tea aerasi sedangkan compost tea yang tidak diaerasi disebut compost tea nonaerasi. Kedua compost tea tersebut memerlukan waktu selama 72 jam untuk pembuatannya. Selanjutnya ekstrak kompos (compost tea) disaring dan siap digunakan. 
Persiapan Media Tanam. Media tanam yang digunakan untuk penanaman kailan adalah campuran antara tanah dan cocopeat masing-masing polybag diisi 500 gram media tanam. Selanjutnya benih kailan ditanam dalam polybag masing-masing berisi 2 benih kailan.

Perlakuan percobaan Perlakuan compost tea dilaksanakan dengan cara menyiramkan cairan compost tea pada media tanam yang sekali dalam seminggu dengan dosis penyiraman $150 \mathrm{ml} /$ polybag. Tanaman kailan dipelihara selama 49 hst.

Pengamatan. Pengamatan parameter pertumbuhan tanaman kailan dilakukan mengikuti metode yang digunakan oleh (Oktaviani \& Sholihah, 2018) pada saat tanaman berumur 49 hari setelah penanaman benih (HST). Pengamatan pertumbuhan tanaman kailan meliputi tinggi tanaman. Pengukuran tinggi tanaman pada saat berumur 35 HST, 42 HST, dan 49 HST.

\section{HASIL DAN PEMBAHASAN}

Pengaruh Perlakuan Compost tea dan Media Tanam Cocopeat Terhadap Pertumbuhan Tinggi Tanaman Kailan. Tinggi tanaman diukur mulai dari pangkal akar sampai ujung daun (Rondonuwo, 2016). Berdasarkan uji ANARA pada taraf nyata 5\% diketahui bahwa perlakuan compost tea (A), media (B) dan waktu (C) pada tinggi tanaman menunjukkan bahwa hampir semua perlakuan termasuk interaksinya memberikan tinggi tanaman yang secara nyata berbeda, kecuali perlakuan interaksi antara compost tea dan media $\left(\mathrm{A}^{*} \mathrm{~B}\right)$ serta interaksi compost tea, media, dan waktu $\left(\mathrm{A}^{*} \mathrm{~B}^{*} \mathrm{C}\right)$ yang tidak menyebabkan perbedaan tinggi tanaman secara nyata.

Tabel 1 menunjukkan hasil uji beda nyata terkecil antar perlakuan menggunakan uji Tukey's pada taraf 5\% untuk semua perlakuan yang menyebabkan tinggi tanaman berbeda nyata.

Tabel 1. Hasil Uji Tukey Antar Perlakuan Compost tea, Media Cocopeat dan Waktu Terhadap Tinggi Tanaman Kailan.

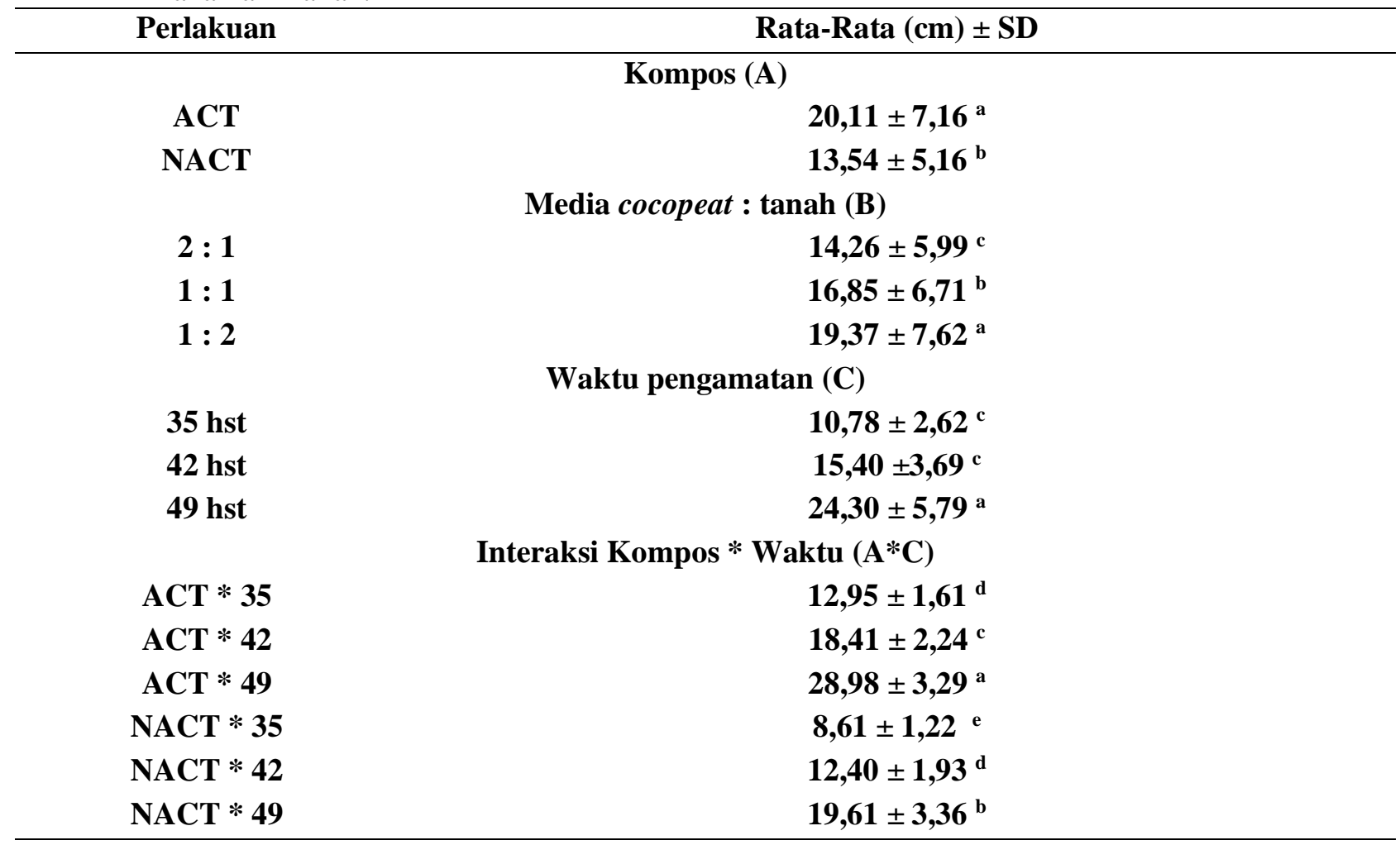




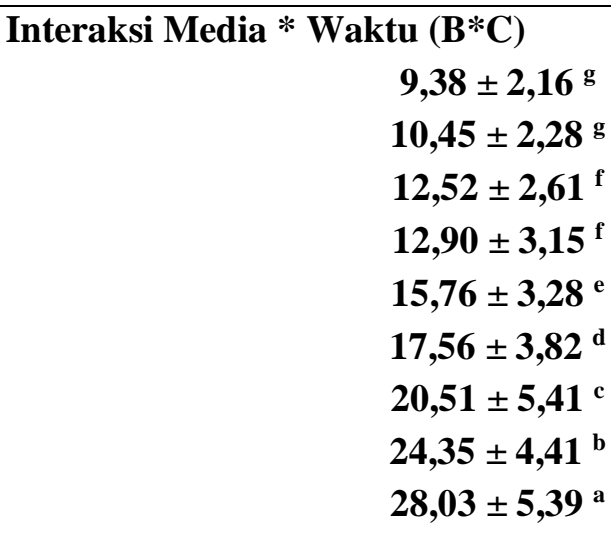

Keterangan $\quad$ : ACT $=$ Aerated Compost tea $;$ NACT $=$ Non-Aerated Compost tea $;$ HST $=$ Hari Setelah Tanam 2:1 = 334 gram Cocopeat:166 gram Tanah; 1;1= 250 gram Cocopeat:250 gram Tanah; 1:2= 166 gram Cocopeat: 334 gram Tanah. (Angka yang diikuti dengan huruf berbeda menunjukkan adanya perbedaan yang nyata antar perlakuan berdasarkan hasil uji BNT menggunakan uji Tukey's pada taraf 5\%).

Berdasarkan Tabel 1 dan Gambar 1 dapat dilihat bahwa compost tea aerasi (ACT) menghasilkan tanaman yang secara nyata lebih tinggi yaitu $20,11 \mathrm{~cm}$ daripada tanaman yang diberi perlakuan compost tea nonaerasi (NACT) yaitu 13,54 cm. Media tanam yang menghasilkan tanaman tertinggi adalah media tanam dengan perbandingan cocopeat $:$ tanah $=1: 2$ yaitu $19,37 \mathrm{~cm}$ dan yang terendah adalah media tanam dengan perbandingan cocopeat $:$ tanah $=2: 1$ yaitu $14,26 \mathrm{~cm}$. Demikian pula dengan perlakuan waktu berpengaruh secara nyata pada tinggi tanaman. Tanaman yang tertinggi pada saat berumur 49 hst yaitu $24,30 \mathrm{~cm}$ dan tanaman yang terendah pada saat berumur 35 hst yaitu $10,78 \mathrm{~cm}$.

Perlakuan interaksi compost tea dan waktu $\left(\mathrm{A}^{*} \mathrm{C}\right) \mathrm{ACT}$ menghasilkan tanaman paling tinggi yang berumur 49 hst yaitu $28,98 \mathrm{~cm}$ (Tabel 1). Perlakuan interaksi media tanam dan waktu $\left(\mathrm{B}^{*} \mathrm{C}\right)$ menghasilkan tanaman tertinggi yang diberi perlakuan perbandingan cocopeat : tanah $=1: 2$ dan berumur 49 hst yaitu 28,03 cm (Tabel 1). Hasil ini sesuai dengan hasil penelitian Marin et al. (2014) yang menunjukkan bahwa ACT dari semua sumber mampu meningkatkan pertumbuhan tanaman lada dan menekan dibandingkan perlakuan NACT, meski keduanya dianggap efektif. Penggunaan ACT lebih kuat dalam meningkatkan kesuburan tanah, dan meningkatkan pertumbuhan tanaman (Ingham, 2005). Selanjutnya hasil penelitian Ma'rufah (2020) pupuk organik dari limbah cair hasil pembuatan gula tebu (vinnase) memberikan hasil yang berpengaruh nyata terhadap tinggi tanaman bunga kol (Brassica oleracea var. Botrytis L.).

Media tanam cocopeat juga berpengaruh nyata pada tinggi tanaman kailan. Hal ini sesuai dengan hasil penelitian Simanjutak \& Heddy (2018) yang menunjukan bahwa media tanam cocopeat yang dicampur tanah berpengaruh nyata pada tinggi tanaman horenso (Spinacia oleracea L). Menurut Rahmi (2018) yang menyatakan cocopeat mampu mempengaruhi sifat fisik tanah dalam hal meningkatkan ketersediaan air dan oksigen bagi tanaman, memperbaiki struktur tanah, sehingga mempermudah perkembangan akar.

Pada perlakuan waktu berpengaruh secara nyata pada tinggi tanaman. Waktu berpengaruh pada tinggi tanaman karena pertambahan tinggi suatu tanaman merupakan akibat adanya perkembangan daerah meristematik dimana pada daerah ini terjadi pembelahan sel secara terus menerus menghasilkan sel-sel yang baru. Pertumbuhan meristem berlangsung terus menerus jika suplai air, nutrisi, karbon dioksida dan sinar matahari oleh daun diolah menjadi makanannya sendiri yang biasa disebut proses Fotosintesis. Air bersama-sama zat hara diserap oleh akar dan naik ke atas melalui xilem menuju ke daun dan karbon dioksida diserap dari udara melalui stomata padapermukaan daun. Adanya sinar matahari dan dengan adanya butir-butir klorofil, air dan karbon dioksida dipaduhkan menjadi gula sebagai sumber energi untuk pertumbuhan tanaman. Selanjutnya pembelahan sel-sel pada meristem ujung berfungsi untuk 
memperpanjang batang pokok. Produksi sel-sel baru pada lokasi meristem diikuti oleh pemanjangan sel-sel sehingga menambah tinggi tanaman (Fitter \& Hay, 1992).

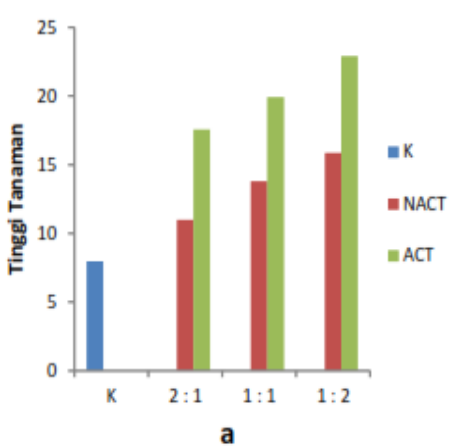

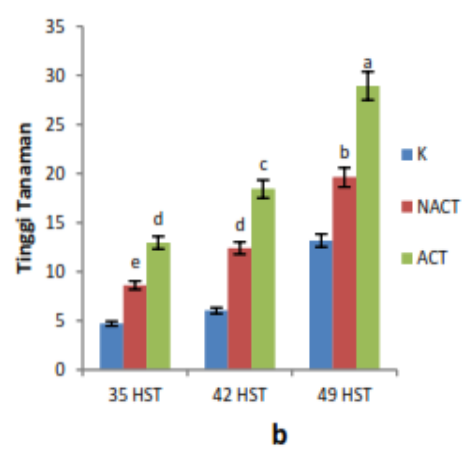

b

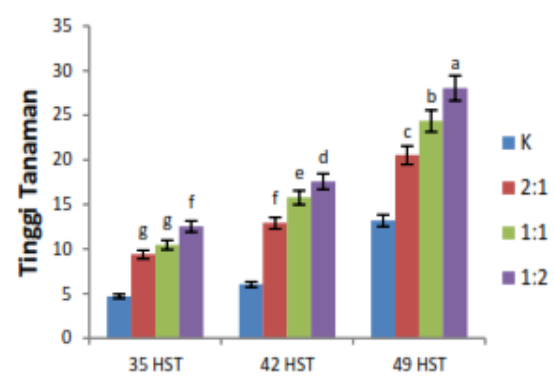

c

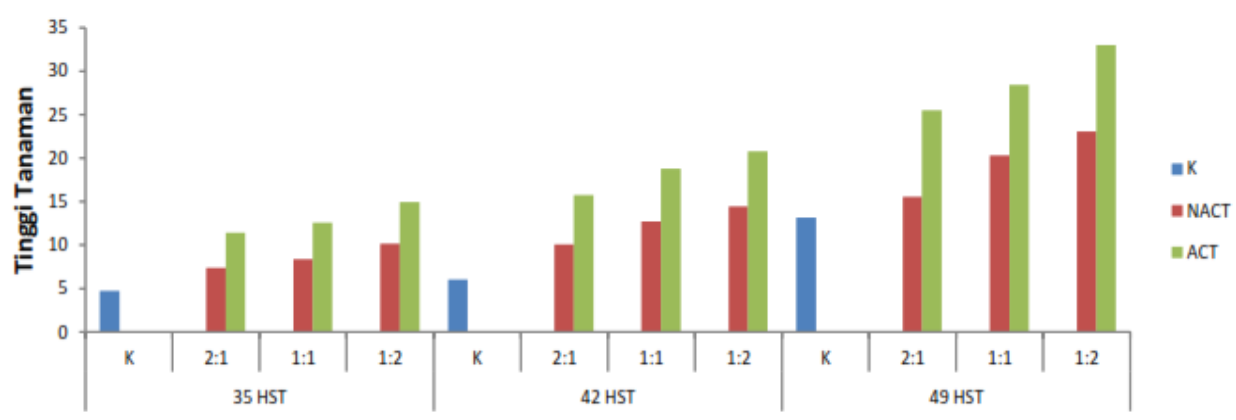

d

Gambar 1. Tinggi tanaman kailan sebagai akibat perlakuan interaksi compost tea dan media tanam cocopeat yang diukur pada waktu yang berbeda. a. Interaksi compost tea dan media tanam cocopeat terhadap tinggi tanaman kailan, b. Interaksi compost tea dan waktu terhadap tinggi tanaman kailan, c. Interaksi media tanam cocopeat dan waktu terhadap tinggi tanaman kailan, d. Interaksi compost tea, media tanam cocopeat, dan waktu terhadap tinggi tanaman kailan.

\section{Keterangan :}

$\mathrm{K}=$ Kontrol $; \mathrm{ACT}=$ Aerated Compost tea $; \mathrm{NACT}=$ Non-Aerated Compost tea $; \mathrm{HST}=$ Hari Setelah Tanam $2: 1=334$ gram Cocopeat:166 gram Tanah; 1;1= 250 gram Cocopeat 250 gram Tanah; 1:2=166 gram Cocopeat: 334 gram Tanah.

Perlakuan interaksi compost tea dan waktu $\left(\mathrm{A}^{*} \mathrm{C}\right)$ yang menghasilkan tanaman tertinggi adalah tanaman yang diberi ACT dan berumur 49 hst yaitu 28,98 cm, sedangkan tinggi tanaman yang terendah diperoleh dari perlakuan NACT dan berumur 35 hst yaitu 8,61 cm (Gambar 1b). Perlakuan interaksi media tanam dan waktu $\left(\mathrm{B}^{*} \mathrm{C}\right)$ yang menghasilkan tanaman tertinggi adalah tanaman yang diberi ACT yang berumur 49 hst yaitu 22,89 cm, sedangkan tanaman yang terendah diperoleh dari perlakuan NACT yang berumur 35 hst yaitu 10,99 cm (Gambar 1c).

Perlakuan interaksi media dan waktu $\left(\mathrm{B}^{*} \mathrm{C}\right)$ dan perlakuan interaksi compost tea, media, dan waktu $(A * B * C)$ tidak berpengaruh secara nyata pada tinggi tanaman. Namun, bila dilihat dari rata-rata tinggi tanaman untuk setiap perlakuan tersebut (Gambar 1a dan d) maka dapat dilihat perlakuan interaksi media tanam dan waktu $\left(\mathrm{B}^{*} \mathrm{C}\right)$ yang cenderung menghasilkan tanaman tertinggi yaitu pelakuan perbandingan cocopeat : tanah =1:2 dan berumur 49 hst, sedangkan tanaman yang terendah diperoleh dari perlakuan perbandingan cocopeat : tanah $=2: 1$ dan berumur 35 hst (Gambar 1a). Pada perlakuan interaksi compost tea, media dan waktu $\left(\mathrm{A}^{*} \mathrm{~B}^{*} \mathrm{C}\right)$, perlakuan compost tea aerasi $(\mathrm{ACT})$ dan media tanam cocopeat $:$ tanah $=1: 2$ yang berumur 49 hst cenderung menghasilkan tanaman tertinggi dan perlakuan compost tea nonaerasi 
(NACT) yang ditanam pada media tanam cocopeat : tanah $=2: 1$ dan berumur 35 hst cenderung menghasilkan tanaman yang terendah (Gambar 1d).

\section{KESIMPULAN DAN SARAN}

Perlakuann compost tea dan media tanam cocopeat mampu meningkatkan parameter tinggi tanaman dibandingkan tanaman kontrol dan interaksi compost tea aerasi (ACT) pada media tanam cocopeat $:$ tanah $=$ 1:2 memberikan hasil terbaik pada pertumbuhan tanaman kailan (Brassica oleracea L.).

Penelitian lebih lanjut perlu dilakukan tentang pengaruh compost tea dan media tanam cocopeat terhadap pertumbuhan tanaman kailan dengan cara foliar yaitu menyemprotkan langsung cairan compost tea ke daun tanaman dan perlu dilakukan uji lanjut kandungan unsur hara yang terdapat pada compost tea.

\section{DAFTAR PUSTAKA}

Antonius, S., Maman, R. \& Dwi, A. M. 2015. Pemanfaatan inokulan mikroba sebagai pengkaya kompos pada budidaya sayuran. Jurnal Berita Biologi, 14(3), pp. 223-234.

Berek, A. K. 2017. Teh Kompos dan Pemanfaatannya sebagai Sumber Hara dan Agen Ketahanan Tanaman. Jurnal Savana Cendana, 2(4), pp. 68-70. doi: 10.32938/sc.v2i04.214.

Bria, D. 2016. Pengaruh Jenis dan Konsentrasi Teh Kompos terhadap Pertumbuhan dan Hasil Bayam Merah (Alternanthera amoena Voss). Jurnal Savana Cendana, 1(03), pp. 108-111. doi: 10.32938/sc.v1i03.56.

Diah Karunia Binawati. 2012. Pengaruh Media Tanam Terhadap Aklimatisasi Angrek Bulan. Jurnal Wahana, 01, pp. 60-68.

Fitter A.H. dan R.K.M. Hay. 1992. Lingkungan Tanaman. Terjemahan: Sri Andani dan Purbayanti. Yogyakarta: Gadjah Mada University Press.

Ingham, E. R. 2005. The Compost tea Brewing Manual; Latest Methods and Research.5th edn. Fifth Edit.

Krisnawati, D., Triyono, S. and Kadir, M. Z. 2014. Pengaruh Aerasi Terhadap Pertumbuhan Tanaman Baby Kailan (Brassica oleraceae var. achepala) pada Teknologi Hidroponik Sistem Terapung di dalam dan di luar Greenhouse. Jurnal Teknik Pertanian Lampung, 3PENGARUH(3), pp. 213-222.

Ma'rufah, S., Rusdiana, R. Y. and Sari, K. 2020. Pemanfaatan Vinasse sebagai Pupuk Organik Cair untuk Meningkatkan Pertumbuhan dan Hasil Bunga Kol (Brassica oleracea var . Botrytis L.). Jurnal Penelitian Pertanian Terapan, 20(1), pp. 18-24.

Marin, F., F. Dianez., Santos M., Carretero, Gea, F., F. J., Castaneda, C., Navarro, M. J. and Yau, J. 2014. Control of Phytophthora capsici and Phytophthora parasitica on pepper (Capsicum annuum L.) with compost teas from different sources, and their effects on plant growth promotion. Jurnal Phytopathologia Mediterranea, 53(2), pp. 216-228.

Nova K. Rondonuwo, Jeanne Paulus, A. P. 2016. Aplikasi Pupuk Organik Cair Terhadap Pembentukan Krop Tanaman Kubis (Brassica oleracea var capitata L.). Jurnal Eugenia, 22(1), pp. 21-28.

Oktaviani, E. and Sholihah, S. M. 2018. Pengaruh pemberian Plant Growth Promoting Rhizobacteria (PGPR) terhadap pertumbuhan dan hasil tanaman kailan (Brassica oleraceae var. acephala) sistem vertikultur. Jurnal Akbar Juara, 3(1), pp. 63-70. 
Pinatih, I. D. A. S. P., Kusmiyarti, T. B. and Susila, K. D. 2015. Evaluasi Status Kesuburan Tanah Pada Lahan Pertanian di Kecamatan Denpasar Selatan. E-Jurnal Agroteknologi Tropika, 4(4), pp. 282-292. Available at: http://ojs.unud.ac.id/index.php/JAT.

Pracaya. 2005. Kol alias Kubis. Penebar Swadaya. Jakarta. 96 Hal.

Rahmi, Y., N. N. and Ariani, E. 2018. Pengaruh Campuran Cocopeat dan Rock Phosphate Terhadap Pertumbuhan dan Hasil Tiga Varietas Padi Gogo (Oryza sativa L.) Pada Medium Ultisol. Jurnal Solum, 15(1), pp. 17-25. doi: 10.25077/jsolum.15.1.17-25.2018.

Shrestha, K. and B. Walsh, K. 2012. Microbially Enhanced Compost Extract: Does It Increase Solubilisation of Minerals and Mineralisation of Organic Matter and Thus Improve Plant Nutrition? Journal of Bioremediation and Biodegradation, 2(3), pp. 215-219. doi: 10.4172/2155-6199.1000149.

Simanjutak, P. G. and Heddy, Y. . S. 2018. Respon Tanaman Horenso (Spinacia oleraceae L.) terhadap Media Serbuk Sabut Kelapa (Cocopeat) dan Pupuk Cair Kotoran Kelinci. Jurnal Produksi Tanaman, 6(5), pp. 723-728.

Singh, A. and Sharma, S. 2002. Composting of a crop residue through treatment with microorganisms and subsequent vermicomposting. Bioresource Technology, 85(2), pp. 107-111. doi: 10.1016/S09608524(02)00095-0. 